\title{
OPTIMALIZATION OF AFTERBURNER CHANNEL IN BIOMASS BOILER USING CFD ANALYSIS
}

\author{
Jiri Pospisil*, Martin Lisy, Michal SPILACEK \\ Brno University of Technology, Faculty of Mechanical Engineering, Energy Institute Technická 2896/2, 616 69 \\ Brno, Czech Republic \\ * corresponding author: pospisil.j@fme.vutbr.cz
}

\begin{abstract}
.
This contribution presents the results of parametrical studies focused on the mixing process in a small rectangular duct within a biomass boiler. The first study investigates the influence of a local narrowing located in the central part of the duct. This narrowing works as an orifice with very simple rectangular geometry. Four different free cross sections of the orifice were considered in the center of the duct, namely $100 \%, 70 \%, 50 \%, 30 \%$ of free cross section area in the duct. The second study is focused on the investigation of the influence of secondary air distribution pipe diameter on the mixing process in a flue gas duct without a narrowing.
\end{abstract}

KEYWORDS: CFD analysis; flue-gas; mixing; emissions.

\section{INTRODUCTION}

Increase in the use of renewable energy sources goes hand in hand with requirements on improvements of relevant technologies. Technologies for energy from biomass very often use poor-quality fuels that are fuels with high water content. Improper fuels cause many troubles in the control of the combustion process, and require advanced combustion equipment designs. Besides low quality of the fuels, the industry has to face growing requirements on boiler and combustion technology efficiency, and on decrease of emitted pollutants. Development of combustion technologies is commonly supported with computational simulations which stimulate fast development and savings in the development of prototypes [1].

\section{Conditions of COMBustion PROCESS}

All combustion is a chemical reaction which provides thermal energy from energy chemically bound in the combusted fuel. Combustion is a process of burning a fuel where the fuel burns and produces heat and light. Active combustible matter in the fuel $(\mathrm{C}, \mathrm{H}$, and $\mathrm{S}$ ) reacts with atmospheric oxygen $\left(\mathrm{O}_{2}\right)$. Combustion reactions occur under convenient temperatures and the temperature is the main factor affecting the speed of the process (the higher the temperature, the faster the reaction). Combustion is called burning if accompanied by light effect, such as flames $[2,3]$.

As already stated above, combustion is a reaction of fuel and oxygen contained in the combustion air. Combustion equations provide simplifications for the so-called stoichiometric amount of oxygen necessary for the reaction. However, this amount of oxygen is never sufficient in reality, and the combustion process takes place with a certain amount of excess air, which increases the probability of the reaction. On the other hand, the amount of excess air cannot rise too much. First, it increases the production of $\mathrm{NO}_{x}$, and second, it reduces the temperature in the furnace, which worsens the conditions for combustion of the fuel.

When describing the conditions necessary for an optimum course of combustion reactions, the so-called 3Ts are usually mentioned: time, temperature, and turbulence. The combustible components of the fuel must be in contact with an oxidizer so that the combustion reaction is optimal. The contact must occur under optimum temperature conditions and must last for a specific period of time. Specific parameters are affected by various factors, such as type of fuel, furnace design, pressure in the furnace, etc. Optimization of the three parameters, that are temperature, time, and turbulence, helps decrease the surplus of combustion air $[2,3]$.

Biomass contains a high share of volatile combustible matter (75-80\%) and therefore it is vital to comply with the optimum conditions during the combustion of biomass. Volatile combustible matter is released from the fuel at temperatures exceeding $150{ }^{\circ} \mathrm{C}$; intensive release occurs at $200-250^{\circ} \mathrm{C}$. Further increase in temperature causes burning of the first components of the fuel. Hydrogen and hydrocarbons are ignited at temperatures exceeding $450{ }^{\circ} \mathrm{C}$, and the temperature of the flame steeply rises to 900-1400 ${ }^{\circ} \mathrm{C}$ (depending on fuel moisture content and excess combustion air). Solid combustible components in charcoal are ignited at temperatures around $600^{\circ} \mathrm{C}$. Flame temperatures must be kept at above $900^{\circ} \mathrm{C}$ and a sufficient amount of oxygen must be supplied in order to achieve complete burnout of the combustible $[4,5]$.

All "3T" parameters were considered and analyzed 


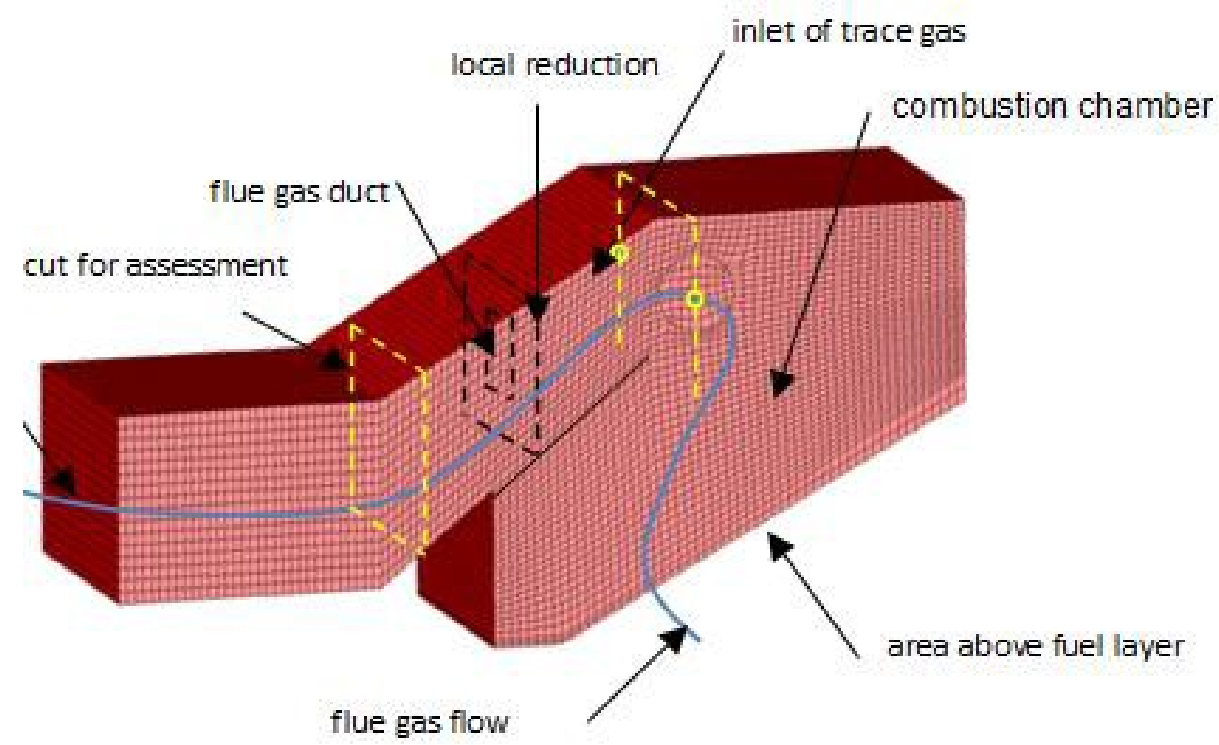

FiguRE 1. Geometry of the area - mesh of control volumes

during development of the technology discussed below. The original combustion chamber had a rectangular cross section with an inclined grate and no builtin internals. The fuel was supplied from one side above the grate and flue gas flow left through the opposite outlet branch. Primary air was supplied under the grate; secondary air was supplied above the grate. A major problem with operating the original technology was mixing of the flue gas flow containing a significant share of combustibles and the combustion air flow, that is an insufficient mixing of the flow under low temperatures in the afterburning and exchanger sections of the chamber. Insufficient mixing resulted in high emissions, especially of CO.

Installing an inclined partition inside the combustion chamber significantly helped to increase the temperature in the chamber and the retention time of the flue gas at high temperature levels (see Figure 1). The partition in the chamber further helped to improve the mixing of air and the released combustible; however, the mixing was insufficient. It was necessary to improve the mixing of the gaseous mixture, especially mixing with the supplied secondary air. There are various technical solutions to this problem.

The simple solutions include a reduction of the channel cross section by using built-in internals with an orifice; the more complicated ones use the so-called static mixer, which is a device for continuous mixing of liquids.

Thorough assessment of available options resulted in opting for the instalment of built-in internal with an orifice. The following procedures helped optimize the shape and location of the orifice so that the mixtures of flue gas and secondary air may be sufficiently mixed.

\section{Computational modelling}

Computational modelling based on the control volume method was used for parametrical study testing the impact of local reduction of the cross section of a flue gas duct on mixing of the flue gas. A computational model of an afterburner channel in a $200 \mathrm{~kW}$ boiler for combustion of wood was built up for the purposes of the study. The geometry of the combustion channel was transposed into a mesh comprising hexagonal volume elements; see Figure 1 .

Flue gas flowing in an unobstructed flue gas duct of a rectangular cross section $(0.72 \times 0.4 \mathrm{~m})$, with no local reduction, was modelled as the initial basic geometrical configuration. Other geometrical configurations resulted from modifications of the basic configuration of the flue gas duct, that is by installing a thin partition with one rectangular orifice with a free section corresponding to $70 \%, 50 \%$, and $30 \%$ of the original unobstructed duct, free cross section of the duct.

\subsection{BOUNDARY CONDITIONS}

Inlet boundary conditions. The inlet was identified at a lateral cross section at the bottom part of the boiler (the grate surface) where flue gas enters the relevant section of the boiler. Uniform inlet velocity of flue gas was set to $10 \mathrm{~m} / \mathrm{s}$, temperature to $750{ }^{\circ} \mathrm{C}$, and flu-gas density to $0.24536 \mathrm{~kg} / \mathrm{m}^{3}$ (at the given surface). A similar boundary condition was used for trace gas injected from the boiler wall. The trace gas entered the flow from the wall level at a velocity of $5 \mathrm{~m} / \mathrm{s}$ and more in the direction perpendicular to the boiler wall. 


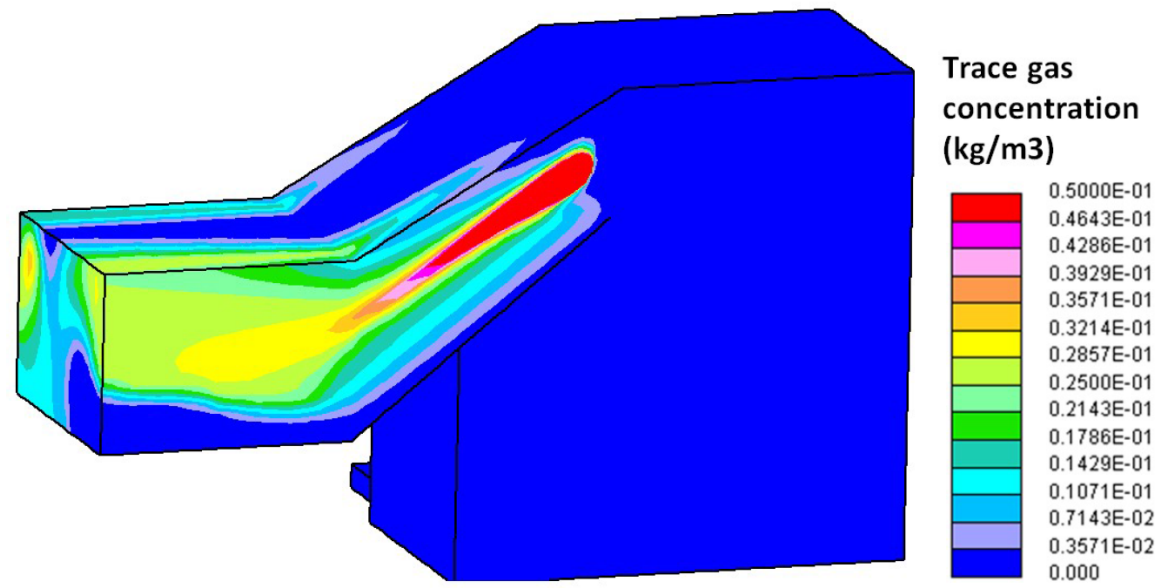

Figure 2. Trace gas concentration close to the flue gas duct walls

\begin{tabular}{|c|c|c|c|c|c|c|}
\hline & \multicolumn{3}{|c|}{ Free cross section in reduction place } & \multicolumn{3}{|c|}{ Concentration in cut } \\
\hline & $\begin{array}{c}\text { Free cross section } \\
(\%)\end{array}$ & $\begin{array}{l}\text { Width } \\
(\mathrm{m})\end{array}$ & $\begin{array}{l}\text { Height } \\
\text { (m) }\end{array}$ & $\begin{array}{l}\text { Minimum } \\
\left(10^{-2} \mathrm{~g} / \mathrm{m}^{3}\right)\end{array}$ & $\begin{array}{l}\text { Maximum } \\
\left(10^{-2} \mathrm{~g} / \mathrm{m}^{3}\right)\end{array}$ & $\begin{array}{c}\text { Average } \\
\left(10^{-2} \mathrm{~g} / \mathrm{m}^{3}\right)\end{array}$ \\
\hline Option 1 & 100 & 0.720 & 0.402 & 0.025 & 6.43 & 1.52 \\
\hline Option 2 & 70 & 0.602 & 0.336 & 0.355 & 4.98 & 1.72 \\
\hline Option 3 & 50 & 0.509 & 0.284 & 0.179 & 3.60 & 1.70 \\
\hline Option 4 & 30 & 0.394 & 0.220 & 0.123 & 2.61 & 1.56 \\
\hline
\end{tabular}

TABLE 1. Values of trace gas concentrations in the assessed cut.

The "pressure" outlet boundary condition. It was set to the outlet surface at the end of the combustion duct in the computational model.

The wall boundary condition. It was set to other surface areas of the model. The solution considers an adiabatic wall with friction.

Turbulence model. The solution used a $\mathrm{k}-\epsilon$ turbulence model.

Pure nitrogen was used as substitute for real flue gas in this study. Nitrogen at a temperature of $750{ }^{\circ} \mathrm{C}$ serves as a nonreactive flow pattern for subsequent study of mixing and dispersion processes. The combustion chamber was modelled with adiabatic walls to simulate isothermal flow behavior. These simplifications enable us to investigate mixing processes with the exclusion of secondary mixing mechanisms caused by chemical reactions or by temperature gradient.

\section{NARROWING THE DUCT}

Flow of a gaseous mixture comprising $5 \%$ hydrogen and $95 \%$ nitrogen, the so-called trace gas, was supplied into the flue gas flow from the side walls of the boiler, $0.4 \mathrm{~m}$ before the local reduction of the duct (see Figure 1 - yellow dots). There were two sources of trace gas, located at the same horizontal line, in the middle of the duct height. Mixing of the flue gas was assessed using concentration maps of the trace gas which were acquired in a vertical cut of the combustion duct $0.5 \mathrm{~m}$ beyond the reduction. 3D fields of trace gas concentration in the combustion equipment were calculated in the parametrical study. A similar boundary setting was used for all analyzed geometry. Examples of concentration fields are given in Figure 2 (no reduction of the flue gas duct).

Assessment of the distribution of trace gas concentrations in the flue gas was done in the vertical cut led $0.5 \mathrm{~m}$ beyond the local reduction of the flue gas duct. Concentration maps of trace gas from this cut are given in Figure 4. The concentration was evaluated by identifying a minimum concentration, maximum concentration, and average concentration. The obtained values of the assessed parameters are given in Table 1 for all researched configurations. The chart in Figure 3 presents an overview of the assessed parameters.

The calculated concentration maps (Figure 4) clearly show a difference in the trace gas concentration distribution for the particular researched options. Option 1 shows two independent flows of trace gas close to the walls where the gas enters the flue gas flow. The flue gas duct without any reduction does not intensify the mixing of gases in the combustion duct. Mixing is thus a consequence of physical and turbulent diffusion. The highest difference between a maximum and minimum concentration at the assessed cut was obtained for option 1.

The local reduction tested in the flue gas duct for 


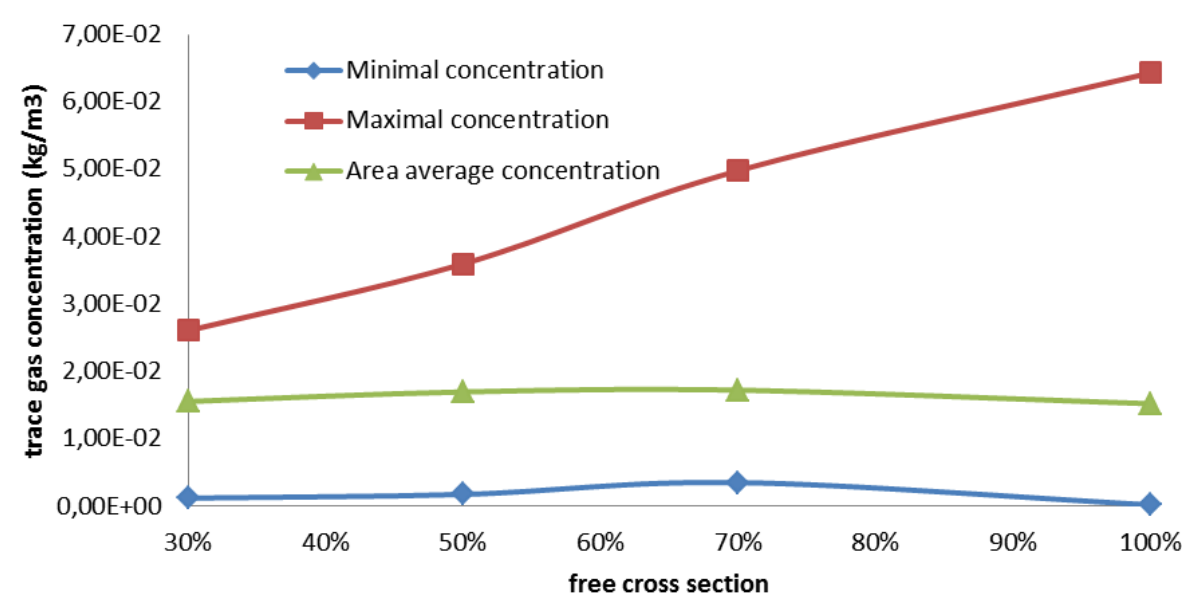

FIGURE 3. Graphical display of maximum, minimum, and average concentration

Options 2-4 shows a different nature of concentrations, but the decrease in maximum concentration in the cut is almost linear. This proves that a reduction of the cross section helps mix the flue gas. The minimum concentrations of all researched options are close to zero. This concentration may be found in parts of the flow which were exposed to the trace gas only minimally.

The average concentration of the trace gas with identical mass of the entering gas should be identical for all options, which is not true for option $2(70 \%$ reduction). The deviation from that assumption may be explained in reference to the use of flat averaging which does not reflect different mass flows of flue gas in various parts of the cross section.

Quantification of the impact of the cross section reduction on the mixing of the gases may stem from a linear decrease in the maximum concentration related to smaller free cross sections. The boundary states of that linearization may be option 1 (no reduction in the duct) with a maximum concentration of $100 \%$, and option 4 (30\% of the free cross section) where the maximum concentration reached $41 \%$ of the maximum free duct concentration.

A reduction of the free cross section of the channel results in an increase in pressure losses. For correct evaluation of pressure losses, the static pressure fields were analyzed for constant mass flux rate of the flue gas. The static pressure values necessary for flowing of flu-gas through the entire boiler were obtained from the carried out parametrical study. The relationship between static pressure drop and the free cross section of the duct is presented in Figure 5

The local reduction of the free cross section does not influence the total retention time of gaseous species in the combustion chamber. The local cross section reduction causes a local increase in flue gas velocity and it forms a very complex structure of the velocity field of flue gas. It results in longer ways of individual streamlines.

Pressure losses and mixing intensity are directly influenced by the actual value of kinetic energy of turbulence. An increase in kinetic energy of turbulence influences the fluid flow character like for a more viscous fluid. More turbulent flow generally results in higher value of pressure drops. More intensive mixing processes are encouraged by a more complex vortex structure of flow with higher kinetic energy of turbulence. The corresponding kinetic energy of turbulence was obtained from the numerical calculations in a position behind the channel reduction - in the position of the evaluating cut. The values of kinetic energy of turbulence obtained from the carried out parametrical study are presented in Figure 6.

Kinetic energy of turbulence generally increases with increasing velocity of flue gas flow. For the studied configuration of flue gas duct, we can investigate the relation between the velocity of flue gas in the orifice of the reduction and kinetic energy of turbulence in the evaluated cut. This relation is expressed by utilizing relative changes in Figure 7

Figure 7 shows that increasing flue gas velocity increases the kinetic energy of turbulence behind the reduction orifice. The significant distance of the assessed cut from the reduction orifice causes the less intensive increase in kinetic energy of turbulence in comparison with the observed flue gas velocity.

\section{SIZE OF SECONDARY AIR DISTRIBUTION PIPES}

The following parametrical study was carried on a numerical model of a flue gas duct without any reduction.

The parametrical modification of the geometry is focused on the testing of changes of the distribution pipe diameter that is used for the supply of trace gas. Four pipe diameters were tested: 50, 100, 150 and $200 \mathrm{~mm}$. The distribution pipe is stacked into the combustion chamber, and ends in the wall surface $0.4 \mathrm{~m}$ before the baffle formed by the vault (same position as for the source of trace gas in the previous chapter). Cool trace gas $\left(15^{\circ} \mathrm{C}\right)$ is supplied in the flow of hot flue gas via a distribution pipe. Mixing 


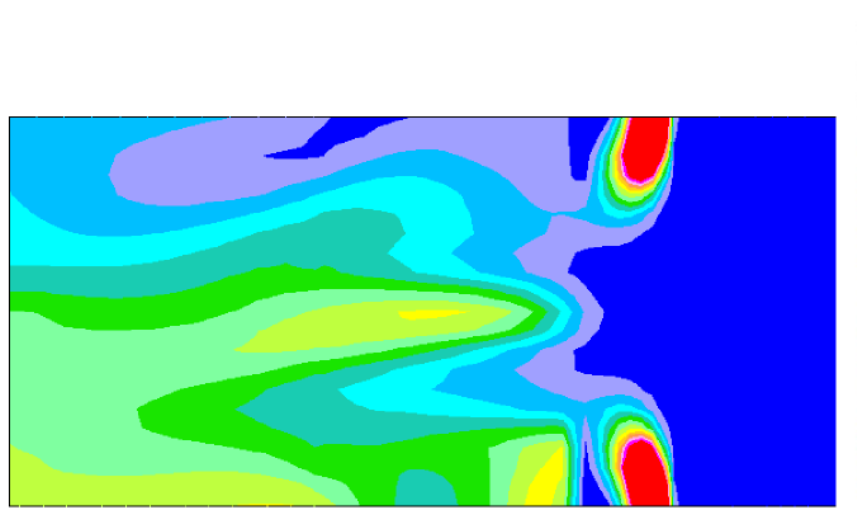

Trace gas

concentration

$(\mathrm{kg} / \mathrm{m} 3)$

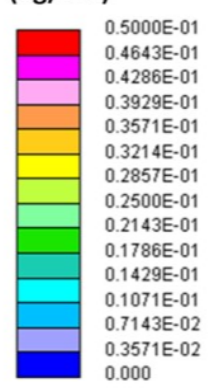

(a)

Trace gas

concentration

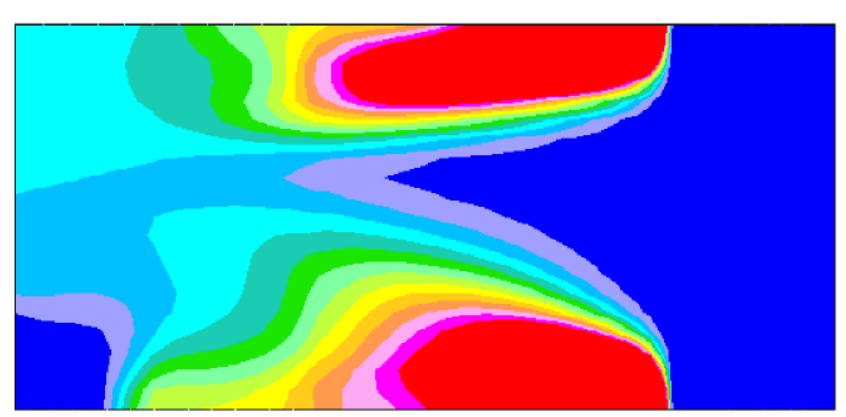

(kg/m3)

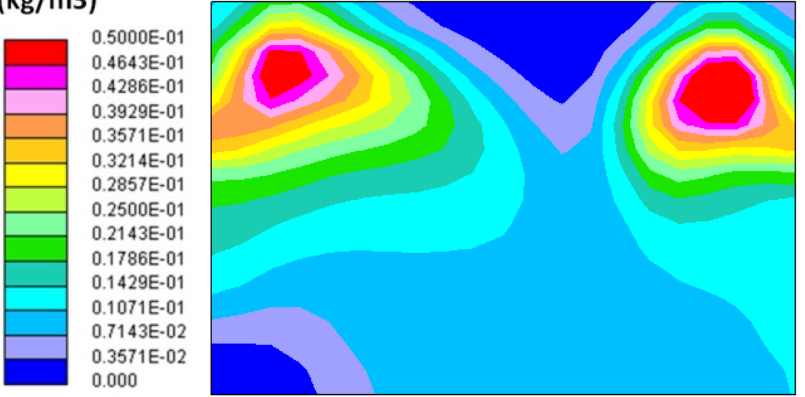

(b)

\section{Trace gas}

concentration

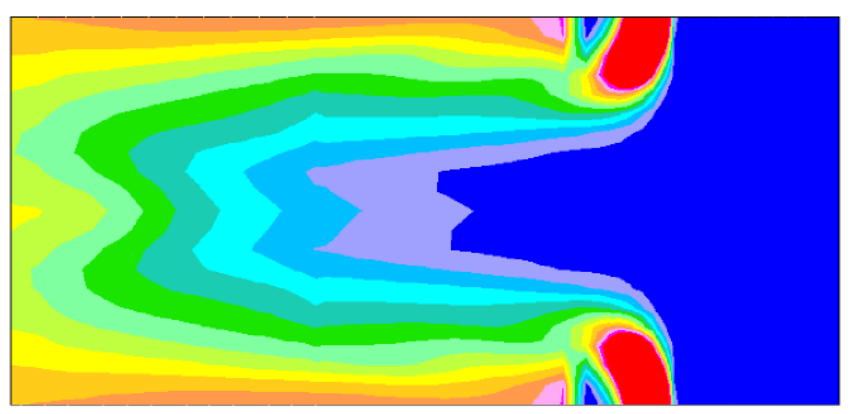

(kg/m3)

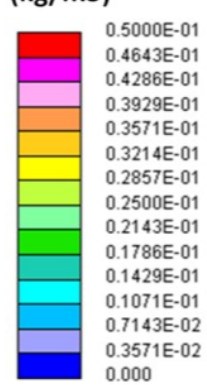

(c)

\section{Trace gas}

concentration

$(\mathrm{kg} / \mathrm{m} 3)$
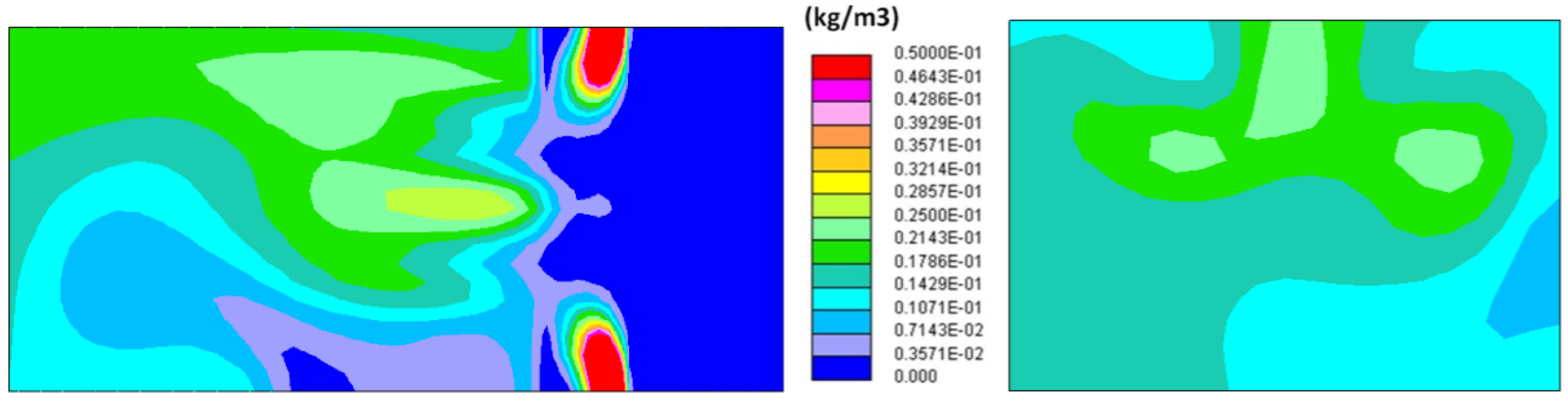

(d)

FiguRE 4. Concentration of trace gas in the cut of maximum concentrations. Left of each subfigure: highest concentrations - section plan view; right: concentration in the cut - view in the direction of flue gas flow. a) Option 1 - free cross section $100 \%$; b) Option 2 - free cross section $70 \%$; c) Option 3 - free cross section $50 \%$; d) Option 4 free cross section $30 \%$. 


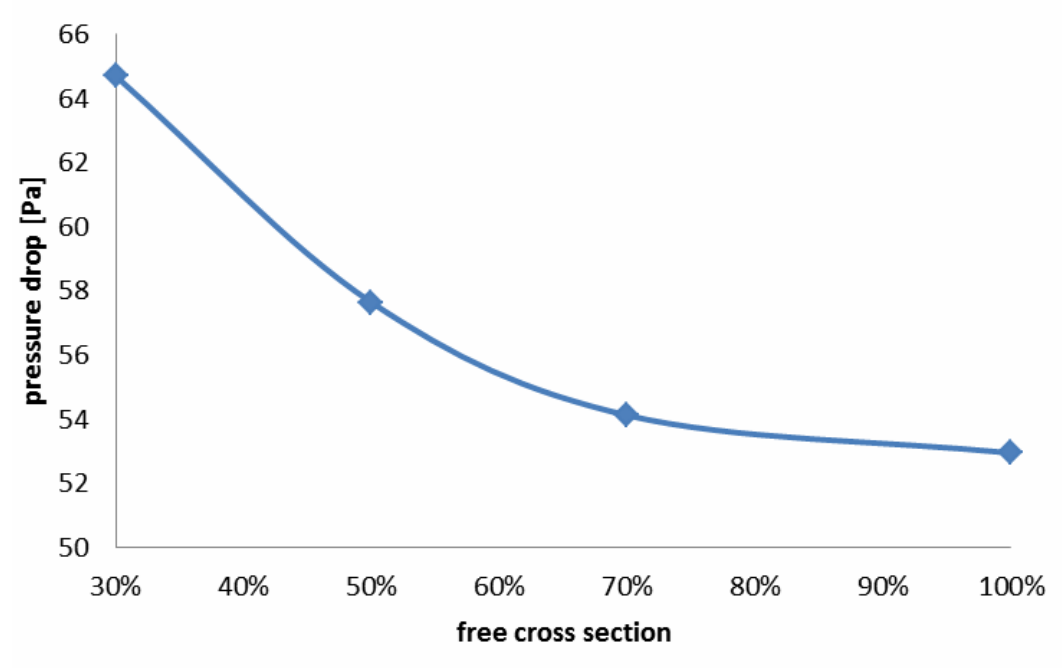

FiguRE 5. Relationship between the static pressure drop and the free cross section

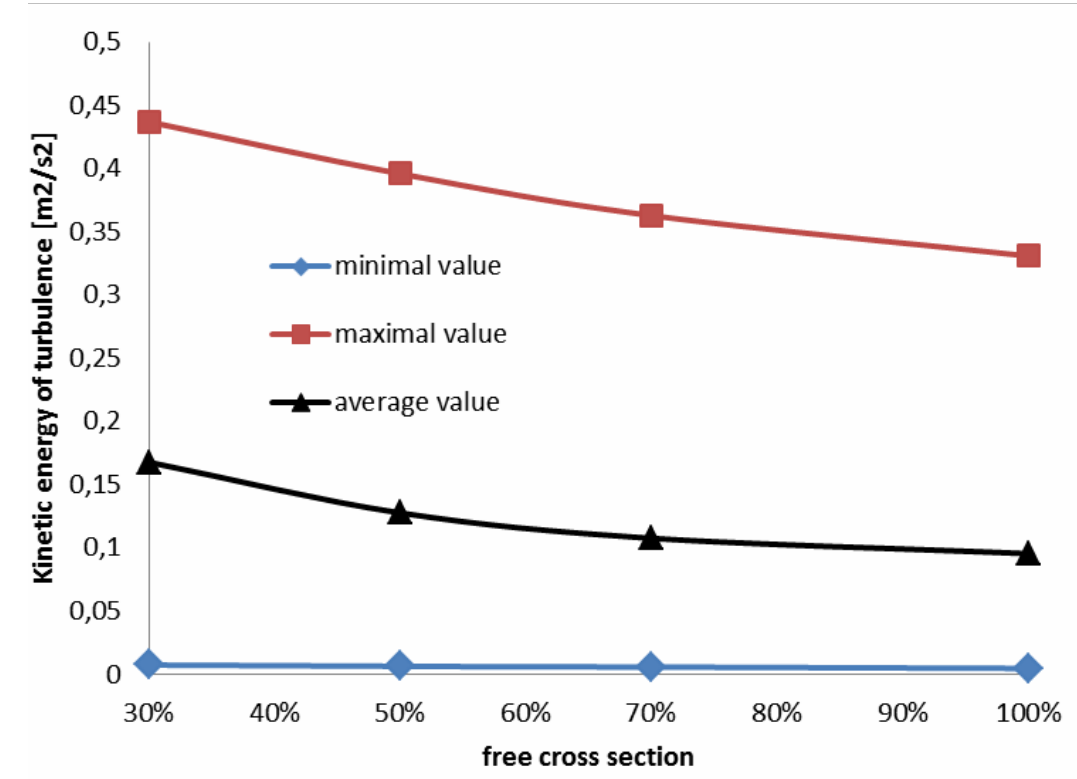

FIgURE 6. Relationship between the kinetic energy of turbulence and the free cross section

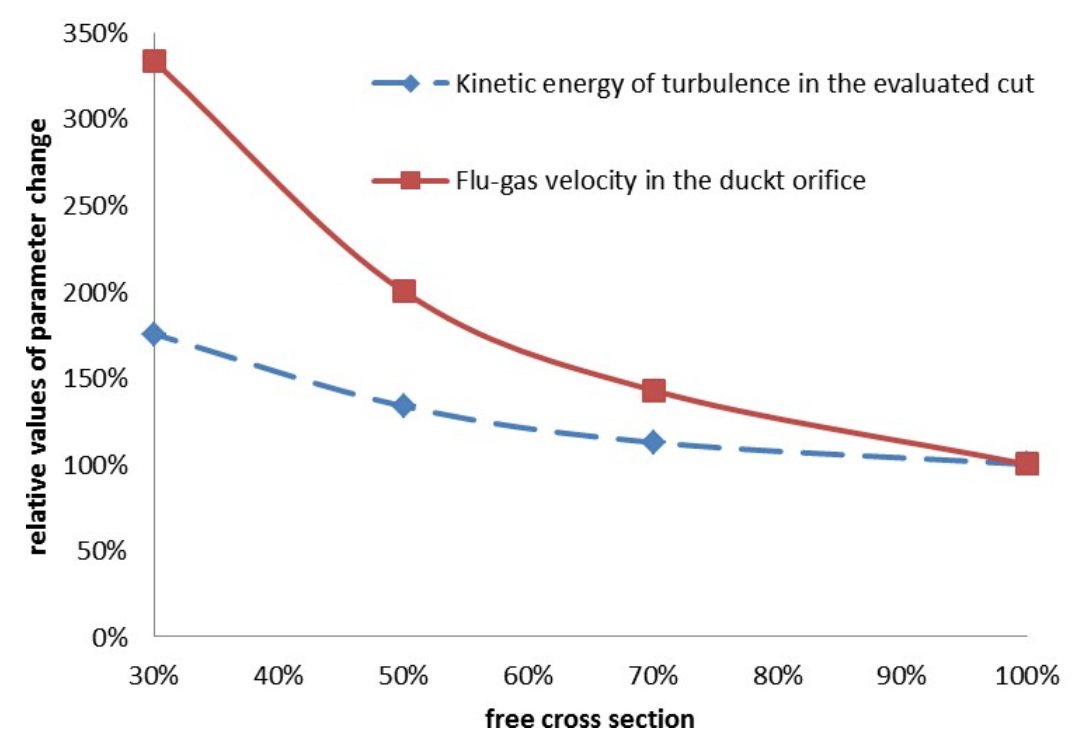

Figure 7. Relative changes of kinetic energy of turbulence in the assessed cut and flue gas velocity in the duct orifice. 


\begin{tabular}{ccccccc}
\hline \multicolumn{2}{c}{ Secondary air } & & \multicolumn{3}{c}{ Concentration in the assessed cross section } \\
\cline { 1 - 2 } $\begin{array}{c}\text { Pipe diameter } \\
(\mathrm{mm})\end{array}$ & $\begin{array}{c}\text { Injection velocity } \\
(\mathrm{m} / \mathrm{s})\end{array}$ & & $\begin{array}{c}\text { Minimum } \\
(\mathrm{vol} \%)\end{array}$ & $\begin{array}{c}\text { Maximum } \\
(\text { vol\% })\end{array}$ & $\begin{array}{c}\text { Difference } \\
(\text { vol\%) }\end{array}$ & $\begin{array}{c}\text { Average } \\
(\text { vol\%) }\end{array}$ \\
\hline 200 & 5.1 & & 18 & 68 & 50 & 36 \\
150 & 9.1 & & 26 & 61 & 35 & 36 \\
100 & 20.4 & & 22 & 48 & 27 & 34 \\
\hline
\end{tabular}

TABle 2. Comparison of options for constant mass flow.
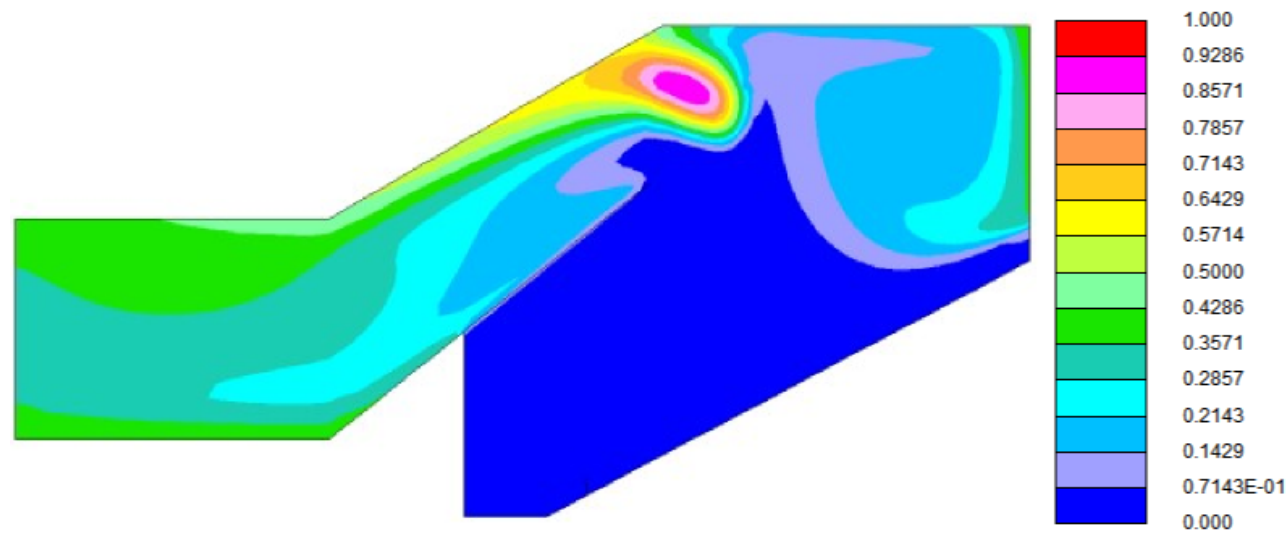

FiguRE 8. Example of trace gas distribution

of the flows of flue gas and trace gas was analyzed using concentration maps of hydrogen (the trace gas compound) obtained from a vertical cross section of the flue gas duct, performed before the second twist of the flue gas duct; see the yellow cross section in Figure 1 .

$3 \mathrm{D}$ concentration fields of trace gas were obtained from computation. No active chemical reactions were considered in this parametrical study. Hydrogen worked as a trace gas for assessment of the mixing quality and its visualization. The same model setting was used in all four geometry options, which differed in the diameter of the distribution pipe for the secondary air.

The distribution of trace gas in flue gas was assessed in the vertical cross section before the second twist of the flue gas duct, $0.7 \mathrm{~m}$ before the end of the modeled duct. An example of the obtained concentration field of trace gas in the central cross section of the duct is given in Figure 8 for a diameter of trace gas distribution pipe of $100 \mathrm{~mm}$ and trace gas velocity of $5.1 \mathrm{~m} / \mathrm{s}$.

The calculated concentration map for the velocity of $5.1 \mathrm{~m} / \mathrm{s}$ clearly shows the character of concentration distributions of trace gas for the particular analyzed distribution pipe diameter. If the trace gas is distributed through a bigger cross section (bigger diameter), more of the flue gas duct is affected by trace gas with a local maximum concentration in the lower part of the flue gas duct. A decrease in the diameter of the trace gas pipe and same flow velocity of trace gas cause shifts of the local maximum concentration into the upper part of the assessed flue gas duct. When the smallest diameter of the trace gas pipe was tested, the local maximum concentration of trace gas was in close vicinity of the top surface of the flue gas duct. These changes are a result of a change in the flow distribution that is affected by a collision of flue gas flow and secondary combustion air flow. This conclusion may be generalized for all analyzed velocities of the entering secondary air.

Figure 9 shows a comparison of the average concentrations of trace gas for all four analyzed diameters of distribution pipes.

Dependencies in the results obtained for different inlet velocities of trace gas were acquired by a detailed quantification of the lowest and highest concentrations of trace gas in the analyzed cross section. It is obvious that the difference between the minimum and maximum concentration increases with an increase in the diameter of the distribution pipe of the trace gas. This dependency is displayed in more details in Figure 10. The particular difference ranges from ca. $10-12 \%$ for a distribution diameter of $50 \mathrm{~mm}$ (velocity has no impact) to $50 \%$ difference for a diameter of $200 \mathrm{~mm}$ and the lowest velocity of $5.1 \mathrm{~m} / \mathrm{s}$.

Minimum concentration is another important parameter which may be identified. The higher air velocity, the higher the values of minimum concentration of trace gas. The minimum concentration of trace gas is close to zero for the smallest pipe diameter and for velocities of 5.1 and $9.1 \mathrm{~m} / \mathrm{s}$. This means that there are places in the cross section which are not affected by the flow of trace gas. The minimum concentration does not drop below $10 \%$ for highest trace gas velocities of $20.4 \mathrm{~m} / \mathrm{s}$. 


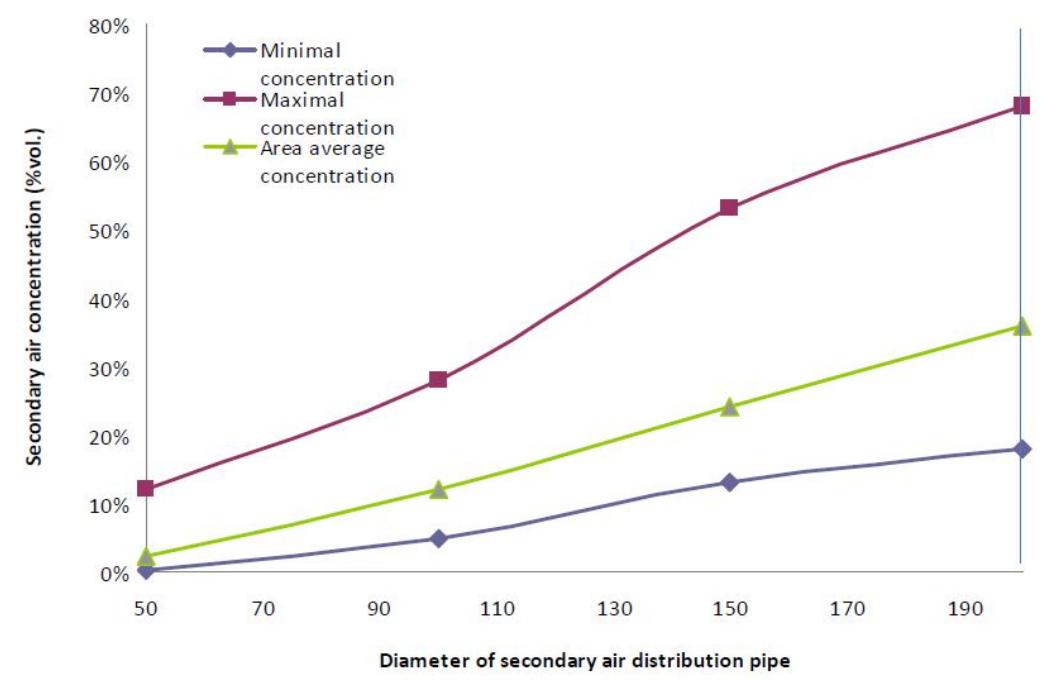

Figure 9. Assessment of concentrations of trace gas (secondary air) for inlet velocity of air of $5.1 \mathrm{~m} / \mathrm{s}$

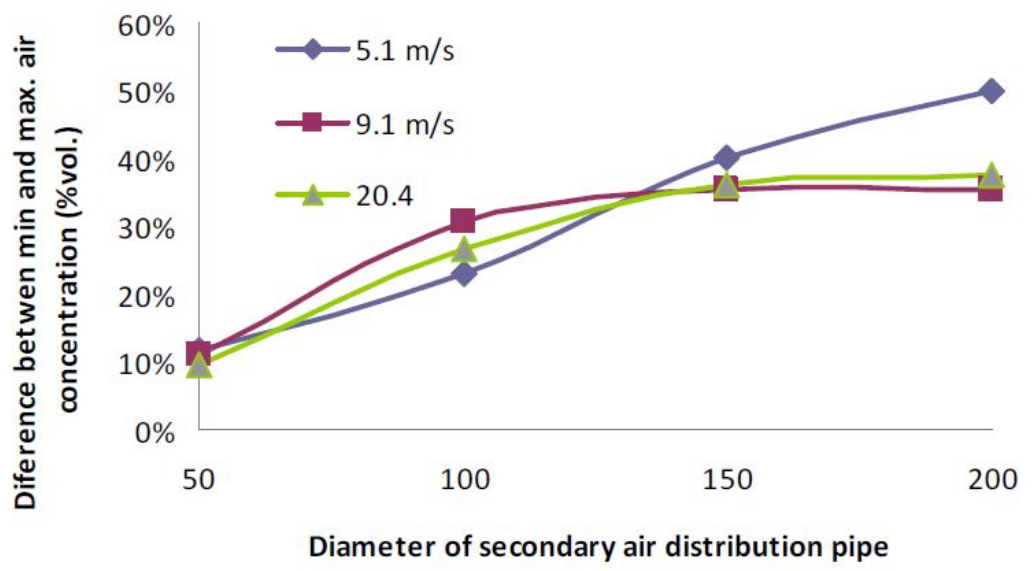

FIGURE 10. Difference of minimum and maximum concentrations of trace gas

\section{Conclunsions}

The carried out parametrical study aimed to increase the retention time of flue gas in the gasification chamber and intensify the mixing of flue gas flow with secondary air. Using the computational tool StarCD, we designed a system of built-in internals for the regulation of flue gas flow in the chamber equipped with a turbulator, which significantly helps mix the flue gas flow with combustion air. The main task was to identify the impact of reduction of the duct on the quality of mixing of flue gas and secondary air flows. Mathematical modelling clearly shows a linear dependency of the duct reduction on flow mixing, and a decrease in the maximum concentration of secondary air (substituted by trace gas) in the duct.

In terms of practical applications, the optimum options seem to be between $50 \%$ and $30 \%$ of cross section reduction. The solution with the $30 \%$ reduction of the flue gas duct was performed and tested in practice. Emissions of pollutants significantly decreased and comply with emission limits stipulated in the most stringent class 5 according to EN 3035. CO emissions were lower than $100 \mathrm{mg} / \mathrm{m}_{\mathrm{n}}^{3}$; OGC ranged in the $2-3 \mathrm{mg} / \mathrm{m}_{\mathrm{n}}^{3}$, interval, and $\mathrm{PM}$ reached c. $30-40 \mathrm{mg} / \mathrm{m}_{\mathrm{n}}^{3}$.

The second objective of the analyses was to observe the impact of diameter of a secondary air supply pipe and secondary air velocity on the mixing of the secondary air with flue gas in the combustion chamber without a narrowing. In this study secondary air was substituted by trace gas. Distribution of the same amount of secondary air using more distribution pipes with smaller diameters may be recommended. In general, higher velocity of distributed air enhances mixing processes and results in more uniform concentration of air in afterburning duct.

\section{ACKNOWLEDGEMENTS}

This work is an output of research and scientific activities of NETME CENTRE PLUS (LO1202) enabled by financial means from the Ministry of Education, Youth and Sports under the "National Sustainability Programme I".

\section{REFERENCES}

[1] Yevgeniya, H., Reinhard, L., Horst, M., Aliya, A.: CFD code FLOREAN for industrial boilers simulations 
(2009) WSEAS Transactions on Heat and Mass Transfer, 4 (4), pp. 98-107.

[2] J. Horák, P. Kubesa: The combustion of solid fuels in local heating (1), cited from:

http://energetika.tzb-info.cz/8618-o-spalovani-

tuhych-paliv-v-lokalnich-topenistich-1,

[2015-03-20].

[3] J. Horák, P. Kubesa: The combustion of solid fuels in local heating (2), Cited from:

http://energetika.tzb-info.cz/8644-o-spalovani-

tuhych-paliv-v-lokalnich-topenistich-2,

[2015-03-20].

[4] Z. Lyčka: Wood Pellet II., combustion in a local boilers, Krnov, (2011). 